\title{
The Good, the Better, and the Best in Political Science
}

\author{
Michael J. Ballard, University of New Mexico \\ Neil J. Mitchell, University of New Mexico
}

$T_{\text {tition }}^{\text {he }}$ here is no rhadamanthine solution to the problem of comparing the research performance of departments, and there is no shortage of interest in the topic. Institutionally, a favorable ranking provides graduate and faculty recruitment benefits. Individually, rankings provide an outlet for the competitive spirit lurking behind good academic manners. Here, we provide a measure of political science department productivity that, while not capturing the whole of the story, has some advantages over other rankings.

The recent National Research Council's (NRC) rankings of research doctorate programs in the United States has generated some critical analyses by political scientists. The principal component of the NRC's rankings was department reputation, constructed from the perceptions of faculty evaluators in the spring of 1993 (National Research Council 1995). Analyses of the NRC rankings demonstrated that some of the more important factors accounting for the variation in reputation are department size and the overall reputation of the university (Katz and Eagles 1996; Jackman and Siverson 1996; Lowery and Silver 1996). In other words, there are extraneous influences on these reputation-based rankings that

Michael J. Ballard was a doctoral candidate in political science at the University of New Mexico. His research focuses on the efficiacy of market-based approaches to environmental regulaiton, and is currently pursuing this interest in the graduate program of the Department of City and Regional Planning at Cornell University.

Neil J. Mitchell is professor and chair of the department of political science at the University of New Mexico. His teaching and research are in the area of comparative politics and he is the author of The Conspicuous Corporation (University of Michigan Press, 1997). complicate their interpretation, at least as indicators of faculty quality and productivity.

The NRC study had data on number of publications, but, noting that these data do not control for journal quality, Miller, Tien, and Peebler (1996) focused on publications in the American Political Science Review, as well as on citations. While a welcome supplement to the reputational analyses, their focus on the discipline's preeminent journal itself represents an overcorrection for the problems with the NRC data. This ranking leaves out much high-quality research. As with any discipline, political science has a broad range of refereed journals, several of which can claim a visibility and authority comparable to the American Political Science Review. These journals are included in this analysis.

In this way we follow the lead of Welch and Hibbing (1983; see also McCormick and Bernick 1982), although with a somewhat different list of journals. Drawing on Garand's rankings (1990), political science journals that achieved a mean rating by a random sample of political scientists of 6 or above on a $0=$ poor to $10=$ outstanding scale, and a proportion familiar score of 0.5 or above, are included in the analysis. Thus, our analysis is based upon articles published in American Political Science Review, Journal of Politics, American Journal of Political Science, World Politics, Comparative Politics, British Journal of Political Science, Western Political Quarterly/Political Research Quarterly, Polity, and Political Science Quarterly.' Faculty publications in the form of articles, research notes, and controversies (APSR) are included for the period 1986-96, discounting for the number of coauthors. Thus, a department receives a 1 for each article, research note or controversy authored by one of its faculty, .5 if coauthored (with someone from a different department), and so on.

Table 1 presents the department research performance rankings. Departments are ranked by a weighted total publication score over the average number of full-time faculty members over this period (WTFAC). Relatively small differences in the publication scores can lead to rank changes for the top fifty, but the best or most productive five departments do separate quite clearly from the rest.

Publications are weighted for the quality of the journal. For this quality weighting, we employ Garand's "journal impact" measure (1990). For faculty size, we averaged the data reported for each department in the American Political Science Association, Graduate Faculty and Programs in Political Science (1986, 1992, 1995). Per capitizing publications is necessary to control for the distortion of sheer faculty size on the measurement of faculty research performance.

How does this measure of research performance compare with the perceptions of research performance reported in the NRC study? While most of the top fifty publishing departments are in the NRC top 50 , only one graduate program receives the same ranking by either measure, and there is no statistically significant relationship between the two measures. ${ }^{2}$ Examining column five (CHANGE), one can see the impact of the more objective measure. Some universities, including Cal Tech, Carnegie-Mellon, Texas A\&M (the leading department by raw publication score), the University of New Mexico, Marquette, and West Virginia, were unranked by the NRC. For others that were included, like SUNY-Stony Brook, Iowa, 
Table 1

The Top 50 Political Science Departments

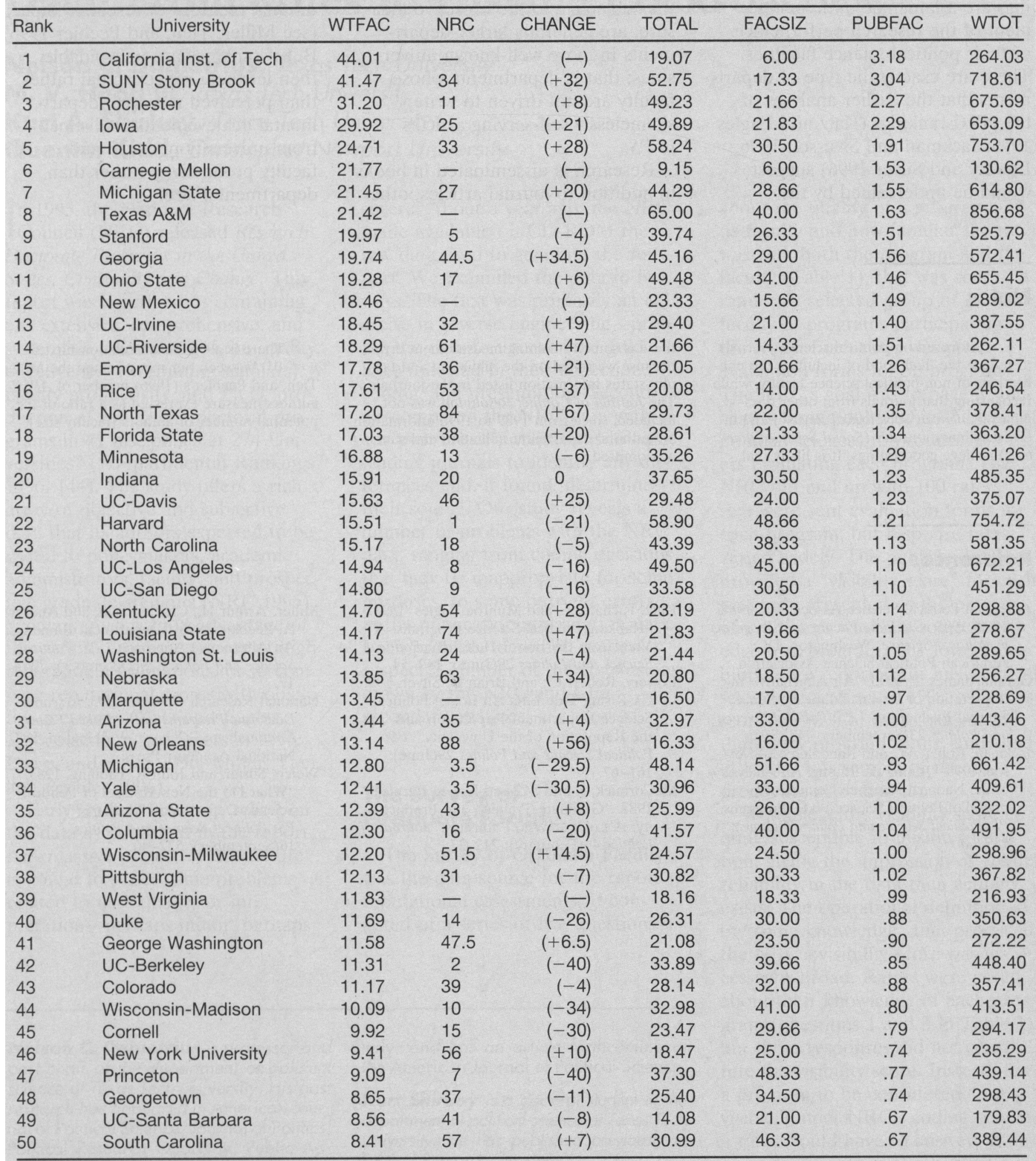

NRC $=1993$ NRC rankings for political science departments

CHANGE $=$ Number of places up or down, our rankings versus the NRC

WTFAC $=$ WTOT/FACSIZE $=$ Department score for publications per faculty member, controlling for journal quality

TOTAL $=$ Raw score for number of publications in top journals

FACSIZE $=$ Average number of political science faculty, 1986-96

PUBFAC $=$ TOTAL/FACSIZ $=$ Publications per faculty member

WTOT $=$ Publications weighted by Garand's (1990) journal impact score 
Houston, Rice, the University of California, Riverside, North Texas, or Louisiana State, the NRC rankings are a lamentable understatement of the research performance of their political science faculties. These are exactly the type of departments that the earlier analyses of the NRC rankings (Katz and Eagles 1996; Jackman and Siverson 1996; Lowery and Silver 1996) suggest would be undervalued by the

\section{Notes}

1. We focused on political science journals to reduce the likelihood of including the publications of non-political science faculty, while recognizing that journals from other disciplines (American Sociological Review) and interdisciplinary journals (Social Science Quarterly) achieve good ratings. It is likely that

\section{References}

American Political Science Association. 1986. 1992. 1995. Graduate Faculty and Programs in Political Science. Washington, DC: American Political Science Association.

Garand, James C. 1990. "An Alternative Interpretation of Recent Political Science Journal Evaluations." PS: Political Science and Politics 23(September): 448-51.

Jackman, Robert W., and Randolph M. Siverson. 1996. "Rating the Rating: An Analysis of the National Research Council's Appraisal of Political Science Ph.D. Programs." PS: Political Science and Politics 29(June): 155-60. subjective measure: relatively small and located in universities with little cachet. The big losers, moving from the subjective to the objective measure, are generally larger departments in more well-known universities; that is departments whose faculty are not driven to write shamelessly self-serving articles in $P S$.

Research is disseminated in books in addition to journal articles, other

there is some remaining measurement error because we relied on the affiliation and faculty status information listed in the journals. The Journal of Conflict Resolution was not included, since from 1989 to 1996 information on authors' department affiliation and status was omitted. journals may deserve inclusion, and one could also make an argument for incorporating citations as an additional measure of research impact (see Miller, Tien, and Peebler 1996). But if rankings are unavoidable, then let them reflect actual rather than perceived research, departmental achievements as distinct from university prestige, and faculty productivity rather than departmental size.
2. There is a significant relationship, .63 $p<.01$, between our measure and the Miller, Tien, and Peebler's (1996) number of $A P S R$ authors measure expressed as a ratio of the potential number of authors (faculty size).
Katz, Richard S., and Munroe Eagles. 1996. "Ranking Political Science Programs: A View from the Lower Half." PS: Political Science and Politics 29(June): 149-54. Lowery, Robert C., and Brian D. Silver. 1996. "A Rising Tide Lifts All Boats: Political Science Department Reputation and the Reputation of the University." PS: Political Science and Politics 29(June): 161-67.

McCormick, James M., and E. Lee Bernick. 1982. "Graduate Training and Productivity: A Look at Who Publishes." Journal of Politics 44(February): 212-27.
Miller, Arthur H., Charles Tien, and Andrew A. Peebler. 1996. "Department Rankings: An Alternative Approach." PS: Political Science and Politics 29(December): 70417.

National Research Council. 1995. Research Doctorate Programs in the United States: Continuity and Change. Washington, DC: National Academy Press.

Welch, Susan, and John R. Hibbing. 1983. "What Do the New Ratings of Political Science Departments Measure?" PS: Political Science and Politics 16(September): 532-40. 